\title{
SCIDOC
}

\author{
International Journal of Dentistry and Oral Science (IJDOS) \\ ISSN: 2377-8075
}

\section{Prevalence Of Anemia In Completely Edentulous Women: A Retrospective Study}

Research Article

Dhanraj Ganapathy ${ }^{1 *}$, Rangeela ${ }^{2}$, Deepika Rajendran ${ }^{3}$

${ }^{1}$ Professor Department of prosthodontics Saveetha Dental College, Saveetha Institute Of Medical and Technical Science, Saveetha University. 162, Poonamallee High Road Chennai, India.

${ }^{2}$ Saveetha Dental College, Saveetha Institute Of Medical and Technical Science, Saveetha University 162, Poonamallee High Road Chennai, India. ${ }^{3}$ Senior lecturer Department of oral medicine and radiology Saveetha Dental College, Saveetha Institute Of Medical and Technical Science, Saveetha University. 162, Poonamallee High Road Chennai, India.

\section{Abstract}

\begin{abstract}
Anemia is a condition in which Haemoglobin concentration and RBC number are lower than the normal. Anemia is associated with increased morbidity of the world's population. Females were consistently at greater risk of anemia than men across almost all geographic regions in most age groups. The oral aspect of aging as related to nutritional and vitamin deficiencies, have been reviewed in dental literature, where in many of the degenerative changes seen in the oral cavity may be due to loss of essential nutrients. 134 patients were examined for the study. Each patient's demographic details, haemoglobin status were noted under certain parameters. Collected data was statistically analysed by a software SPSS. The chi square test for each parameter and correlation were done. It is inferred that 45 to 60 years with completely edentulous status are reported higher in number. A statistically significant correlation was found in between the age group and anemic status of completely edentulous women with a chi square value of $\mathrm{p}<0.05$. With in the limits of the present study the correlation between anemia and age groups was found to be statistically significant with a $\mathrm{p}$ value of $<0.05$. The present study reveals anemia is more common among 45 to 60 age grouped completely edentulous females. Anemia is easily preventable as well as treatable and the available measures are relatively affordable. This study shows a strong relation between edentulism and anemia.
\end{abstract}

Keywords: Women; Completely Edentulous; Anemia; Age Groups.

\section{Introduction}

Anemia is a condition in which Haemoglobin $(\mathrm{Hb})$ concentration and or red blood cell (RBC) numbers are lower than the normal and insufficient to meet an individual's physiological need and affects roughly one third of the world population [21]. Anemia is associated with increased morbidity and mortality in women, $[8,17]$ with poor birth outcome, decreased work productivity in adults.

Establishing appropriate $\mathrm{Hb}$ thresholds to define anemia which is essential for ensuring that anemia is correctly identified, and it's negative effects are prevented. Females were consistently at a greater risk of anemia than men across almost all geographic regions and in most age groups [31]. Other at risk groups include the elderly, as the prevalence of anemia among adults over 50 years of age rises with the advancing age [24].

However, there are intra - and inter country variations in the prevalence of complete edentulism among older patients and direct comparison between national samples is difficult because of the impact of various factors like education, economic circumstances, lifestyle, oral health knowledge and beliefs, and attitudes to oral health care [28]. Studies show that edentulism is closely associated with socioeconomic factors which is more prevalent in poor populations especially in women. Other factors contributing to the prevalence of complete edentulism are age, education, access to dental care, dentist/population ratios, and insurance coverage.

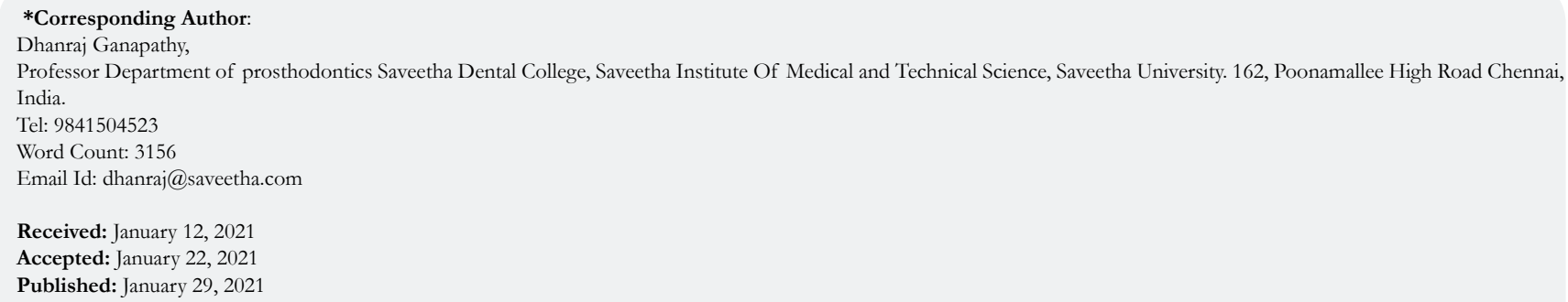

Citation: Dhanraj Ganapathy, Rangeela, Deepika Rajendran. Prevalence Of Anemia In Completely Edentulous Women: A Retrospective Study. Int J Dentistry Oral Sci. 2021;08(01):15421546. doi: http://dx.doi.org/10.19070/2377-8075-21000306

Copyright: Dhanraj Ganapathy ${ }^{\circ} 2021$. This is an open-access article distributed under the terms of the Creative Commons Attribution License, which permits unrestricted use, distribution and reproduction in any medium, provided the original author and source are credited. 
Most edentate people are elders above 40 years of age who wear complete dentures in one or both jaws. Studies have demonstrated that denture wearing continues to increase due to the increase in the aging population; a large number of people still depend on removable dentures for oral function $[9,26]$.

Many nutrient deficiencies common in elderly, including zinc and vitamin B12, seem to result in decreased or modified immune response [30]. Declines in gastric acidity occur with age and cause malabsorption of food bound vitamin B12 [15]. A host of life situational factors increase nutritional risk in elders. With a decline in lean body mass in the elderly, caloric needs decrease and risk of failing increases $[23,16]$. In edentulous patients, some people compensate for decline in masticating ability by choosing cooked food rather than fresh foods and by chewing longer before swallowing. Where as, others may eliminate an entire food group from their diet [11]. These facts explain the etiology of anemia.

The oral aspect of aging as related to nutritional and vitamin deficiencies, have been reviewed in dental literature, where in many of the degenerative changes seen in the oral cavity may be due to loss of essential nutrients [7]. This disability could substantially influence the desire to bite, to chew, and to swallow and could lead to a modification of their food choices. As a result, many researches have consistently demonstrated that tooth loss and dental status have a negative impact on diet and food selection and have resulted in deficiency.

According to several studies, tooth loss can affect general health in several ways as indicated.

lower intake of fruits and vegetables, fibre and increased cholesterol and saturated fat, in addition to a higher prevalence of anemia, can increase the risk of cardiovascular disease and GIT disease [26].

Higher rates of peptic ulcer [34].

Increased risk of non insulin dependent diabetes mellitus [25].

Increased risk of hypertension. A study also demonstrate a possible association between completely edentulism and an increased risk of hypertension [32].

Several longitudinal, prospective and cross sectional studies have supported the association between tooth loss, diet and nutrition. Systemic diseases can impact the successful outcome of several restorative and prosthetic procedures [38] [14, 3, 37, 12, 33, 36, 1,13 18, 19, 2, 4, 20, 10]. Impaired dentition imposes dietary restrictions and affects food eating patterns and results in anemia $[31,34]$. Hence, the aim of this present cross sectional study was to investigate the prevalence and determinant of anemia among edentulous women who visited Saveetha Dental college.

\section{Materials and Method}

The study is a retrospective cross sectional study. This study was conducted among completely Edentulous women who visited Saveetha Dental college and hospital, Chennai. It included demographic data of the patients along with the anemic status of each individual.

\section{Sampling: 134 female completely edentulous patients.}

Data collection: During the period from June 2019 to March 2020 we reviewed the case record of 86000 patients out of which 134 females were completely edentulous were selected for this study. The data collected was classified according to age, gender, anemic status, edentulous area and systemic disease status.

A customised examination was used to collect the data and a special table for data collection was prepared. Data collected were recorded in the excel sheet which was later transferred for statistical analysis using SPSS software. Data were analysed using chi square test. $\mathrm{P}$ value less than or equal to 0.005 was taken as significant.

Inclusion and Exclusion Criteria: All the data was collected including completely edentulous with anemic status in women's, male patients were excluded from this study.

Ethical Approval: The study protocol was approved by the Institutional review board and ethical approval was obtained (SDC/ SIHEC/2020/DIASDATA/0619-0320).

\section{Results and Discussion}

Anemia among women in this large, southern Indian state cuts across social class, place of residence, and other factors that normally discriminate health status. Rich or poor, fat or thin, urban or rural, partial or completely edentulous, the prevalence of anemia is high among women in all these groups. Some studies reveal that low hemoglobin count is associated with blood loss [35]. The bliss loss may be due to menstrual bleeding, digestive or urinary tract, or frequent blood donations. Where as, anemia is a major health threat to the developing countries. Educational programs need to be conducted to improve the public awareness of this problem and its causes. Nutrition education programs should be conducted especially for the women to advocate healthy dietary habits. Screening for iron deficiency in high risk groups should be considered. Primary physician education is needed to ensure a greater awareness and the testing needed to establish diagnosis as well as underlying causes of anemia [27].

The frequency of age distribution of female patients with completely edentulous status who have visited the OP. It is inferred that 45 to 60 years reported higher in number (Figure 1). Figure 2 shows the frequency of edentulous areas in women who've visited the op. It is inferred that both arch edentulous reported higher in number than a single arch edentulousness.

Figure 3 depicts the association between the age groups and anemic status. It is inferred that anemia is seen in around 45 to 60 age grouped females. They were found to be statistically significant. They showed positive correlation with a $\mathrm{p}$ square value of 0.0024 which is less than $\mathrm{p}$ value $=0.05$, statistically significant (Table 3). Anemia is seen around 45 to 60 age grouped females (Figure 3) and this correlates with the result given by Lee et al, [22]. Reported more than $75 \%$ of participants showed prevalence of anemia more common among 52 years old females. Thus this evidence added to the consensus for this study and can be used as a reliable criteria for the association between edentulous and anemic women. 
Figure 1. This figure represents the frequency of age distribution of the patients that were included in the study. Here, $\mathrm{X}$ axis represents the different age groups and $\mathrm{Y}$ axis represents the frequency of participants. Patients who belong to the age group of 45 to 60 showed the highest followed by 60 to 75,30 to 45 and above 75 years.

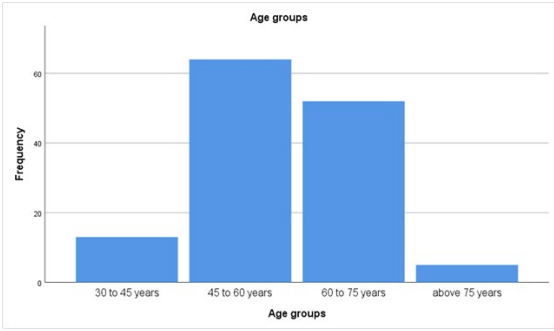

Figure 2. This figure represents the frequency distribution of edentulous area in female patients that were included in the study. Here, $\mathrm{X}$ axis represents the edentulous area and $\mathrm{Y}$ axis represents the frequency of the total number of participants. It is inferred that both arch edentulous reported higher than single arch edentulous (86\%).

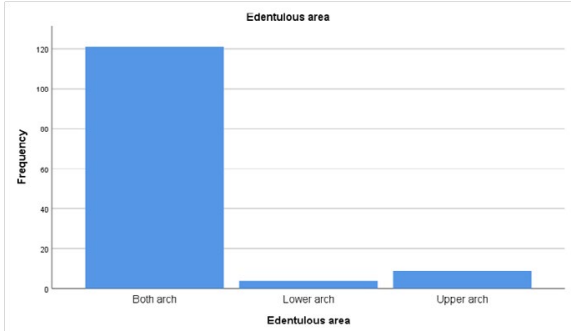

Figure 3. This figure represents the descriptive distribution showing the association between the age group and anemic status of the patient that were included in the study. Here, $\mathrm{X}$ axis represents the anemic status and $\mathrm{Y}$ axis represents the frequency of age groups. This graph shows the higher prevalence of anemia in 45 to 60 years $(89 \%)$.

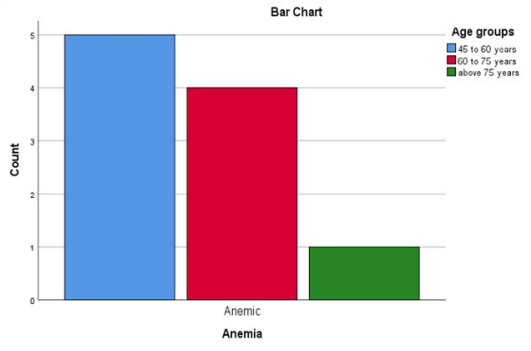

Table 3. Chi square correlation between age groups and anemic status.

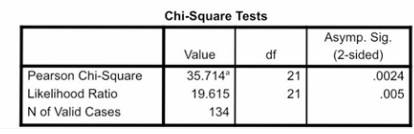

According to this study, the prevalence of edentulous is more common in 45 to 60 age groups $(47.8 \%)$. Figure 4 illustrates the association between edentulous areas and age groups. Chi square correlations were done between age groups and edentulous area. $\mathrm{P}$ value was 0.096 , which is statistically non significant (Table 4). This value is similar to the results derived by campos et al [6] with a prevalence of edentulous in the 50 year old age group.

According to the studies Nowjack - Raym et al [29] and Brennan RM et al [5], they suggested that the most commonly seen systemic disease in edentulous patients is diabetes $(>65 \%)$. The association between systemic disease and different age groups is illustrated in Figure 5, it is seen in the majority of the cases, most commonly seen systemic disease in edentulous patients is diabetes. Chi square correlations were done between age groups and systemic disease. $\mathrm{P}=0.24$, which is statistically non significant (Table 5).

Interventions like iron and folic acid supplementation and other strategies such as diet modification, infection control, nutritional education must be undertaken. Anemia is more prevalent among women in old age. Patients must be monitored periodically, iron supplements and diet or nutritional counselling should be given.

Limitations of study: The study included short sample size and is a single centred study.

Future scope of our study: The study could be done in a larger population. Preventive measures need to be taken in future to decrease the burden caused by anemia. OHI (oral hygiene instruc- 
Figure 4. shows the association between the age group and edentulous area of patients that were included in the study. Here, $\mathrm{X}$ axis represents the edentulous area and $\mathrm{Y}$ axis represents the frequency of age groups. This graph shows the prevalence of edentulous is more common in 45 to 60 years $(82 \%)$.

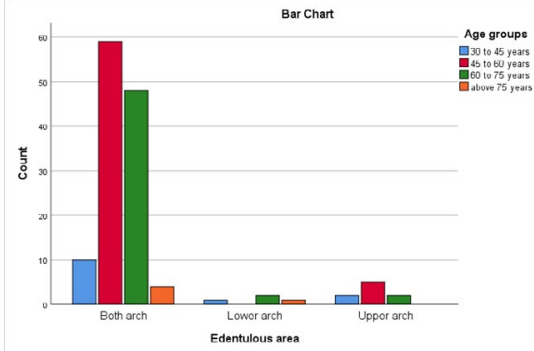

Table 4. Chi square correlation between the age groups and edentulous area.

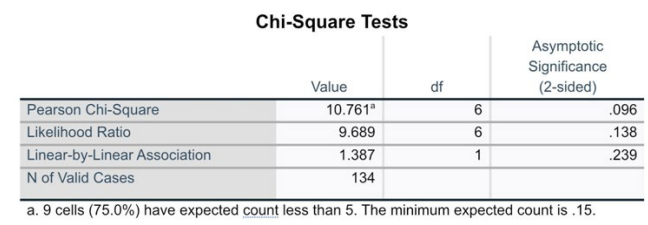

Figure 5. Descriptive distribution showing the association between systemic disease and different age groups. Here, $\mathrm{X}$ axis represents the systemic disease and $\mathrm{y}$ axis represents the frequency of age groups. This graph shows the higher prevalence of diabetes in 45 to 60 years patients $(54 \%)$.

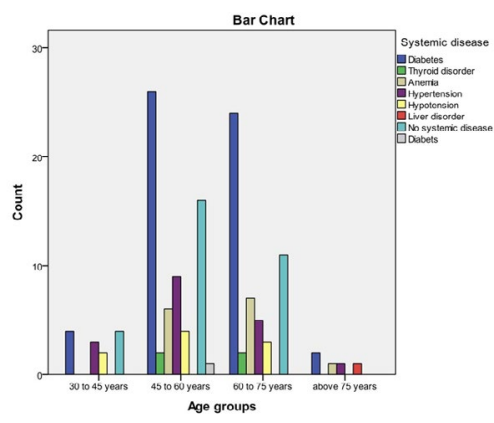

Table 5. Chi square correlation between systemic disease and age groups.

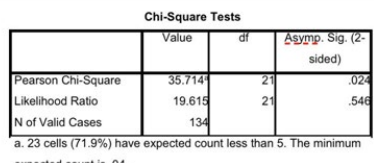

tions) and nutritional counselling should be given to the patients, which would be an ideal measure in the prevention of anemia.

\section{Conclusion}

The present study reveals anemia is more common among 45 to 60 age grouped completely edentulous females. Anemia is easily preventable as well as treatable and the available measures are relatively affordable. This study shows a strong relation between edentulism and anemia. Periodical screening, health check ups and routine hemograms must be performed. The patient should be motivated and educated about the importance of a balanced diet and nutritional supplement. Further studies with a larger sample size are required to estimate the exact prevalence of anemia in a greater population. So that appropriate preventive and treat- ment measures can be initiated.

\section{References}

[1]. Ajay R, Suma K, Ali SA, Kumar Sivakumar JS, Rakshagan V, Devaki V, et al. Effect of Surface Modifications on the Retention of Cement-retained Implant Crowns under Fatigue Loads: An In vitro Study. J Pharm Bioallied Sci. 2017 Nov; 9(Suppl 1): S154-S160. PMID: 29284956.

[2]. Jain AR, Nallaswamy D, Ariga P, Ganapathy DM. Determination of correlation of width of maxillary anterior teeth using extraoral and intraoral factors in Indian population: A systematic review. World J Dent. 2018 Jan; 9: 68-75.

[3]. Ashok V, Nallaswamy D, Benazir Begum S, Nesappan T. Lip Bumper Prosthesis for an Acromegaly Patient: A Clinical Report. J Indian Prosthodont Soc. 2014 Dec; 14(Suppl 1): 279-82. PMID: 26199531.

[4]. Basha FY, Ganapathy D, Venugopalan S. Oral hygiene status among pregnant women. Research Journal of Pharmacy and Technology. 2018 Jul 31; 11(7): 3099-102. 
[5]. Brennan DS, Singh KA, Spencer AJ, Roberts-Thomson KF. Positive and negative affect and oral health-related quality of life. Health Qual Life Outcomes. 2006 Oct 20; 4: 83. PMID: 17052358

[6]. Campos AC, Vargas AM, Ferreira e Ferreira E. Oral health satisfaction among Brazilian elderly: a gender study using a hierarchical model. Cad Saude Publica. 2014 Apr; 30(4): 757-73. PMID: 24896051.

[7]. CDL et al. Prevalence of Nutritional Anaemia among patients reporting to Saveetha Dental College: A SHORT STUDY. International Journal of Advanced Research. 2017; 44-49.

[8]. Chaparro CM, Suchdev PS. Anemia epidemiology, pathophysiology, and etiology in low- and middle-income countries. Ann N Y Acad Sci. 2019 Aug; 1450(1): 15-31. PMID: 31008520.

[9]. Cleary TJ, Hutton JE. An assessment of the association between functional edentulism, obesity, and NIDDM. Diabetes Care. 1995 Jul; 18(7): 1007-9. PMID: 7555531.

[10]. Duraisamy R, Krishnan CS, Ramasubramanian H, Sampathkumar J, Mariappan S, Navarasampatti Sivaprakasam A. Compatibility of Nonoriginal Abutments With Implants: Evaluation of Microgap at the Implant-Abutment Interface, With Original and Nonoriginal Abutments. Implant Dent. 2019 Jun; 28(3): 289-295. PMID: 31124826.

[11]. Emami E, de Souza RF, Kabawat M, Feine JS. The impact of edentulism on oral and general health. Int J Dent. 2013;2013:498305. PMID: 23737789.

[12]. Ganapathy D, Sathyamoorthy A, Ranganathan H, Murthykumar K. Effect of Resin Bonded Luting Agents Influencing Marginal Discrepancy in All Ceramic Complete Veneer Crowns. J Clin Diagn Res. 2016 Dec; 10(12): ZC67-ZC70. PMID: 28209008.

[13]. Ganapathy DM, Kannan A, Venugopalan S. Effect of coated surfaces influencing screw loosening in implants: A systematic review and meta-analysis. World Journal of Dentistry. 2017 Nov;8(6):496-502.

[14]. Gupta A, Dhanraj M, Sivagami G. Status of surface treatment in endosseous implant: a literary overview. Indian J Dent Res. 2010 Jul-Sep; 21(3): 433-8. PMID: 20930358.

[15]. Haurani FI. Microcytic anemia with iron malabsorption. American Journal of Hematology. 1997; 177-177.

[16]. Hilgert JB, Hugo FN, de Sousa Mda L, Bozzetti MC. Oral status and its association with obesity in Southern Brazilian older people. Gerodontology. 2009 Mar; 26(1): 46-52. PMID: 18371171.

[17]. Hruschka DJ, Williams AM, Mei Z, Leidman E, Suchdev PS, Young MF, et al. Comparing hemoglobin distributions between population-based surveys matched by country and time. BMC Public Health. 2020 Mar 30; 20(1): 422. PMID: 32228513.

[18]. Ranganathan H, Ganapathy DM, Jain AR. Cervical and Incisal Marginal Discrepancy in Ceramic Laminate Veneering Materials: A SEM Analysis. Contemp Clin Dent. 2017 Apr-Jun; 8(2): 272-278. PMID: 28839415.

[19]. Jyothi S, Robin PK, Ganapathy D. Periodontal health status of three different groups wearing temporary partial denture. Research Journal of Pharmacy and Technology. 2017 Dec 1; 10(12): 4339-42.

[20]. Kannan A, Venugopalan S. A systematic review on the effect of use of impregnated retraction cords on gingiva. Research Journal of Pharmacy and Technology. 2018 May 30; 11(5): 2121-6.

[21]. Kassebaum NJ, Jasrasaria R, Naghavi M, Wulf SK, Johns N, Lozano R, et al. A systematic analysis of global anemia burden from 1990 to 2010. Blood.
2014 Jan 30; 123(5): 615-24. PMID: 24297872.

[22]. Lee JS, Weyant RJ, Corby P, Kritchevsky SB, Harris TB, Rooks R, et al. Edentulism and nutritional status in a biracial sample of well-functioning, community-dwelling elderly: the health, aging, and body composition study. Am J Clin Nutr. 2004 Feb; 79(2): 295-302. PMID: 14749237.

[23]. De Marchi RJ, Hugo FN, Hilgert JB, Padilha DM. Association between oral health status and nutritional status in south Brazilian independent-living older people. Nutrition. 2008 Jun; 24(6): 546-53. PMID: 18455655.

[24]. Marshall TA, Warren JJ, Hand JS, Xie XJ, Stumbo PJ. Oral health, nutrient intake and dietary quality in the very old. J Am Dent Assoc. 2002 Oct; 133(10): 1369-79. PMID: 12403539.

[25]. Miotti F, Ferro R, Saran G, Grassi L. Malattia diabetica ed edentulia totale: contributo clinico-statistico [Diabetes in the completely edentulous: clinicostatistical study]. G Stomatol Ortognatodonzia. 1985 Oct-Dec; 4(4): $27-9$. PMID: 2951344

[26]. Muller K, Morais J, Feine J. Nutritional and anthropometric analysis of edentulous patients wearing implant overdentures or conventional dentures. Braz Dent J. 2008; 19(2):145-50. PMID: 18568230.

[27]. NA. ) 'Preference of prosthodontics replacement option among partially edentulous patient in rural chennai. International Journal of Current Advanced Research. 2017; 3722-3723.

[28]. Naik AV, Pai RC. Study of emotional effects of tooth loss in an aging north Indian community. ISRN Dent. 2011; 2011: 395498. PMID: 22203909.

[29]. Nowjack-Raymer RE, Sheiham A. Association of edentulism and diet and nutrition in US adults. J Dent Res. 2003 Feb; 82(2): 123-6. PMID: 12562885.

[30]. Pasricha SR, Drakesmith H, Black J, Hipgrave D, Biggs BA. Control of iron deficiency anemia in low- and middle-income countries. Blood. $2013 \mathrm{Apr} 4$; 121(14): 2607-17. PMID: 23355536.

[31]. Ramsey WO. The role of nutrition in conditioning edentulous patients. J Prosthet Dent. 1970 Feb; 23(2): 130-5. PMID: 5262889.

[32]. Sarmento HR, Rodigues PB, Marcello-Machado RM, Pinto LR, Faot F Prosthetic rehabilitation of an edentulous patient with cleft palate. Gen Dent. 2014 Jan-Feb; 62(1): e32-5. PMID: 24401362.

[33]. Selvan SR, Ganapathy D. Efficacy of fifth generation cephalosporins against methicillin-resistant Staphylococcus aureus-A review. Research Journal of Pharmacy and Technology. 2016 Oct 28; 9(10): 1815-8.

[34]. Shah N, Pokharel S, Mishra DR, Adhikari P. Prevalence of Iron Deficiency Anemia in Biochemically Defined Moderate to Severely Anemic patients in a Tertiary Care Centre. JNMA J Nepal Med Assoc. 2019 Sep-Oct; 57(219): 297-301. PMID: 32329451.

[35]. Shigli K, Hebbal M. Does prosthodontic rehabilitation change the eating patterns among completely edentulous patients? Gerodontology. 2012 Mar; 29(1): 48-53. PMID: 21083734.

[36]. Subasree S, Murthykumar K. Effect of aloe vera in oral health-A review. Research Journal of Pharmacy and Technology. 2016 May 1; 9(5): 609.

[37]. Venugopalan S, Ariga P, Aggarwal P, Viswanath A. Magnetically retained silicone facial prosthesis. Niger J Clin Pract. 2014 Mar-Apr; 17(2): 260-4. PMID: 24553044.

[38]. Vijayalakshmi B, Ganapathy D. Medical management of cellulitis. Research Journal of Pharmacy and Technology. 2016 Nov 28; 9(11): 2067-70. 